Annals of Tropical Research 32[1]:31-54(2009)

(c) VSU, Leyte, Philippines

\title{
Floral biology of Jatropha curcas L.
}

\author{
Angelo Jay M. Noriel ${ }^{1}$ and Othello B. Capuno ${ }^{2}$ \\ ${ }^{1}$ Department of Agronomy, 3014C Throckmorton Plant Sciences Center, \\ Kansas State University, Manhattan, KS 66506; \\ ${ }^{2}$ Department of Genetic Resources and Plant Breeding, Visayas State University, \\ Baybay City, Leyte 6521-A, Philippines
}

\begin{abstract}
This study was conducted at the existing plantation of Jatropha curcas within the campus of Visayas State University, Visca, Baybay, Leyte from April 2006 to June 2006 with the following objectives: 1) to study the floral morphology and flowering behavior of J. curcas; 2) to determine the time and duration of flower opening, anther dehiscence, and stigmatic receptivity of $J$. curcas; and 3) to test for pollen viability.

Male and female flowers of $J$. curcas were borne on the same plant with an average numbers per inflorescence of 55.03 and 1.926, respectively. Male flowers were more numerous than the females without definite relationship on number per inflorescence. It took an average of 9.56 days for all florets to full bloom. Anther dehiscence was observed to start at the time of opening of male flowers at around 0500 to 0600 hours and remained so for 24 to 72 hours. Stigmatic receptivity started about 12 hours after full bloom and lasted for about 24 hours. Based on observations, opening of floret buds, anther dehiscence, and stigmatic receptivity were all greatly influenced by the environment. Early sunrise, longer sunshine duration, and less amount of rainfall enhanced flowering of $J$. curcas. Pollen viability was relatively high, ranging from $88.12 \%$ to $98.55 \%$.
\end{abstract}

Keywords: Jatropha curcas, anther dehiscence, stigmatic receptivity, pollen viability, flower opening

Correspondence: A. J. M. Noriel Address: Department of Agronomy, 3014C Throckmorton Plant Sciences Center, Kansas State University, Manhattan, KS 66506. E-mail: ajmnoriel@gmail.com.

DOI: $10.32945 /$ atr3213.2010 


\section{INTRODUCTION}

Jatropha curcas L., locally known as "tuba-tuba", is a member of Euphorbiaceae or the spurge family. It is a drought-resistant perennial growing on marginal soil. It is easy to grow and establish by cuttings or from seed. It has been widely planted in the tropics as a hedge or as a plantation that served different objectives in different countries (Grimm, 1999).

Jatropha curcas also known in English as physic nut is a multipurpose tree or shrub with many potential uses. The seeds produce oil that can be combusted as fuel without being refined. By-product is a press cake, which is a good organic fertilizer. The oil produced is also insecticidal. Sopsop (1991) reported the molluscicidal property of "tubatuba" specifically against golden kuhol (Pomacea canaliculata Lamarck).

In addition, "tuba-tuba" is reported to possess medicinal properties against a number of illnesses such as pneumonia, fever, gonorrhea, hernia, inflammation, paralysis, eczema, dyspepsia, dysentery, and many more (Duke and Wain, 1981). The latex is also used topically forbee and wasp stings (Watt and Breyer-Brandwijk, 1962). In Baybay, Leyte, Philippines, "tuba-tuba" leaves were reported to cure gas pains when pounded and applied as poultice on the abdomen (Noriel et al., 1998). The plant is also used to treat sprains (NSTA, 1982).

The many potentials of $J$. curcas have been adequately established and well-documented. Special interest has been shown in the cultivation of the physic nut for oil extraction, especially since it is drought resistant and can be cultivated on marginal land, without competing with food crop production (Heller, 1996).

Unfortunately, basic information regarding the plant is very limited. Its flowering behavior, for instance, has not yet been studied. This information is very valuable from the standpoint of a plant breeder since it determines specific plant improvement techniques to be used to ensure a more likely successful propagation and breeding schemes. It is also important because it has a bearing on how to grow and sustain the plants. Its availability and sustainability should be of prime importance so that its full potential as source of energy and cure for various illnesses and other possible uses can be realized. 
The experiment dealt on the flowering behavior and characteristics of Jatropha curcas. The study utilized established plants which were ready to flower or already in flowering stage to cope with the time limit of the study. The study was conducted: to study the floral morphology of J. curcas; to determine the time and duration of flower opening, anther dehiscence and stigmatic receptivity of $J$. curcas; and test for pollen viability.

\section{MATERIALS AND METHODS}

\section{Location of experimental area and test plants}

The existing plantation of Jatropha curcas at the College of Engineering and Agri-Industries experimental area, Visayas State University, Visca, Baybay, Leyte was divided into three (3) blocks. Plants were about a year old from planting through cuttings. Plants with at least two (2) inflorescences were randomly selected:

Block 1: 10 plant samples [2 inflorescences per plant

(20 inflorescence samples)]

Block 2: 10 plant samples [2 inflorescences per plant

(20 inflorescence samples)]

Block 3: 7 plant samples [2 inflorescences per plant

(14 inflorescence samples)]

Two inflorescences were sampled assuming a terminal and axillary inflorescences were present in the plant. Those without terminal inflorescence, two axillary inflorescences were selected to have equal samples for each plant. From the sampled inflorescences, 20 individual florets were selected in each block. These samples were used and studied for floral morphology and in determining J. curcas blooming habits.

\section{Data gathered}

Data were collected from the 54 inflorescences and 20 individual florets were selected in each block for flower morphology and blooming habits. Photographs were taken during the course of the study. 


\section{Flower morphology}

From the test plants, data on flower morphology were obtained. Some inflorescences in each sampled plant from each block were gathered and brought to the laboratory for measurement of flower parts such as inflorescence branch, petals, sepals and pedicels. The following parameters were noted: a. Position of inflorescence. Position of inflorescence was observed, whether terminal or axillary; $b$. Number of floret set in every inflorescence. Using the materials above, buds that become fully bloom florets were counted and noted. Each floret bud was followed from bud break until it developed in a fully bloom floret or just fall off. Percent floret set was computed using the formula:

$$
\begin{gathered}
\text { Number of floret set } \\
\text { Total number of floret buds }
\end{gathered}
$$

Number of floret buds per inflorescence.

Based on the same materials as above, the number of florets in every inflorescence was counted and noted; d. Length ( $\mathrm{mm}$ ) of pedicel, petal and sepal. Using an ocular micrometer and compound microscope, the lengths of pedicels, petals and sepals of 20 randomly selected florets were measured. Floret parts were carefully dissected, separated, and laid flat on a glass slide and measured under the microscope; e. Length (mm) of peduncle. Using a vernier caliper, the inflorescence branch arising from the stem was measured. The position of the inflorescence was also noted; and f. Pollen shape. Newly collected pollen was examined under compound electric microscope. The shape was described using standard keys on Morphology and Taxonomy as reference.

\section{Blooming habits}

Live floral specimens were used all throughout data gathering in the field. Inflorescences which were ready to bloom were tagged to determine the blooming habits of J. curcas. Tagged inflorescences and floret buds were observed from 5:00 in the morning until all flowers have bloomed. The following 
data were taken: a. Age at flowering. The age of the plant was recorded when first flowering started; $b$. Number of days required for blooming of all florets in an inflorescence and duration of inflorescence opening. Using the same sample plants, the time required for blooming of all the florets in an inflorescence and duration of inflorescence opening were noted. The time when a bud fully opened (first bloomed floret) and the time when the last bud fully opened were also recorded. Duration of inflorescence opening was noted until wilting of the last bloomed had been observed; $\mathrm{c}$. Time of the day and duration of opening of individual florets. Randomly selected floret buds at a stage estimated to open the following day were tagged and observed. Observation was started at sunrise until floral opening. Duration was determined following these newly opened florets until withering was observed. Likewise, morphological changes such as color and size of the floret were noted. Observation was done on different dates. Block 1: 2nd to 3rd week from the conduct of the study (April 16-29); Block 2: 4th week from the conduct of the study (April 30- May 6); Block 3: 5th week from the conduct of the study (May 7-13); d. Time and duration of anther dehiscence. From 10 tagged male flowers in each block, the time and duration of anther dehiscence were determined. The powdery condition of the anther was used as an index that the anther has already started shedding pollens. Knowing the time of anther dehiscence, the duration of opening of the male flower was observed every after hour for a total of 12 hours or until all pollen grains on the anther were released. Morphological changes were also noted. Visual examination was done too to confirm the observed cessation of anther dehiscence; e. Time and duration of stigmatic receptivity. Ten female flowers expected to bloom the next day were tagged. Changes in color and shape, as well as presence of mucilaginous substance and other observations that would indicate stigmatic receptivity, were determined using the same condition and method used in determining anther dehiscence.

\section{Proper care and sanitation}

Proper care was given to the inflorescences by handling the individual florets gently and lightly. Care was also observed in measuring lengths so as not to tear or break floral parts that would cause reduction in measurements. The laboratory working areas were kept clean all throughout the duration of 
the study. A sanitizing agent, such as alcohol and soap, was used to rub hands and rinse glass slides and Petri dishes before working on the flowers. Glasswares used for pollen testing were washed and sterilized using an autoclave to free from contaminants.

\section{Determination of pollen viability}

\section{Pollen collection}

Pollens were collected from the test plants previously used to determine the blooming habits of $J$. curcas. Male buds at anthesis were plucked early in the morning and placed in glassine bags. The collected buds were brought to the laboratory for pollen testing.

\section{Pollen extraction and testing}

With a sharp-end needle, pollens from the collected buds were extracted and placed on a clean glass slide. A drop of $\mathrm{I}_{2} \mathrm{KI}$ solution was placed on the glass slide with pollens. A cover slip was positioned on top and used to slightly press and evenly distribute the pollens on the glass slide. The total mounted pollens were counted and recorded. Photographs of pollens were also taken using a photomicroscope. Differences in the color of viable (dark blue/violet) and non-viable (yellow) pollens were noted.

Percentage pollen viability.

In pollen testing employing the staining procedure, the percentage of pollen viability was computed using the equation:

Number of stained pollen
Total pollen count

\section{Miscellaneous data}

The following parameters were obtained from the records of the Philippine Atmospheric, Geophysical, and Astronomical Services Administration (PAGASA) Station, VSU, Visca, Baybay, Leyte from the 
conduct to the termination of the study:

a. Daily and total monthly rainfall ( $\mathrm{mm})$;

b. Lowest and highest mean monthly daytime temperatures (C)

c. Monthly total and mean duration of bright sunshine (min)

d. Daily relative humidity (\%)

\section{Statistical analysis}

Data gathered were not analyzed statistically. Only means and standard deviations of the data gathered on the different parameters (as stated previously) were computed. Discussions were based on the actual and visual observations during the conduct of the experiment.

\section{RESULTS AND DISCUSSION}

\section{Floral morphology}

Jatropha curcas flowers are unisexual, regular with greenish white petals. Inflorescences are of cyme arrangement. Male and female florets are borne on the same plant thus being monoecious (Grimm, 1999). The inflorescence produced by the plant could be either arising terminally or axillary, but majority of the flowers were observed to be axillary located on the branch. Terminal inflorescences have short and thick branches that arise from the topmost portion of the plant. On the other hand, axillary inflorescences have long and slender branches that arise form the nodes of the plant where leaves also grow (Figure 1).

It was observed that $J$. curcas has 10 stamens arranged in two distinct whorls of five each in a single column in the andromecium, and in close proximity to each other. In the gynoecium, the three slender styles are connate to about two-thirds of their length, dilating to massive bifurcate stigma. These observations confirmed that of Dehgan and Webster (1979).

Male and female flowers opened simultaneously with at least one bud opening on the first day and generally increased on the succeeding days. In every inflorescence, an average of 55.03 male florets and 1.93 female florets were observed, while an average of $98.25 \%$ was set into full-fledge florets (Tables 1 and 2). Very high standard deviations of 35.84 and 37.44 were 


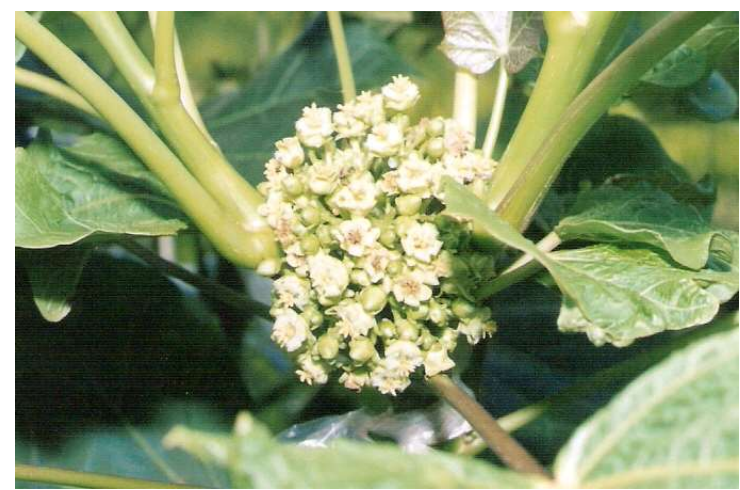

A

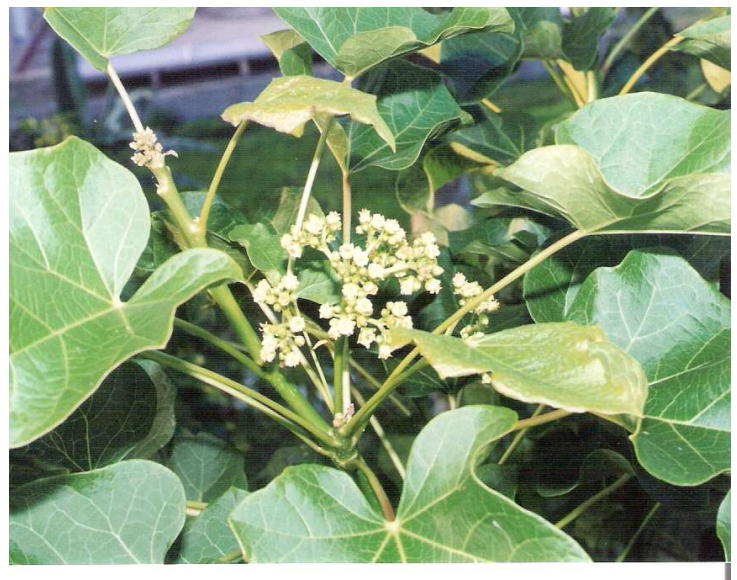

$\mathrm{B}$

Figure 1. Position of inflorescence of $J$. curcas: A. terminal inflorescence; B. axillary inflorescence. 
Table 1. Mean and standard deviation (sd) of the number of male, female and total floret buds of $J$. curcas

\begin{tabular}{llllll}
\hline & & \multicolumn{3}{c}{ Blocks } & \multirow{2}{*}{ Grand mean/sd } \\
\cline { 3 - 5 } & & I & II & III $n n$ \\
\hline \multirow{3}{*}{ Mean } & male & 57.40 & 52.25 & 47.02 & 55.03 \\
& female & 2.10 & 2.10 & 1.43 & 1.93 \\
& total & 59.50 & 60.35 & 48.50 & 56.96 \\
& & & & & \\
\multirow{4}{*}{ sd } & male & 41.69 & 32.33 & 32.77 & 35.84 \\
& female & 2.63 & 2.07 & 1.70 & 2.19 \\
& total & 43.56 & 33.92 & 33.98 & 37.44 \\
\hline
\end{tabular}

Table 2. Mean and standard deviation (sd) of the number floret set of $J$. curcas

\begin{tabular}{lcc}
\hline & Mean floret set (\%) & Standard deviation \\
\hline Block I & 98.53 & 2.19 \\
Block II & 99.06 & 1.37 \\
Block III & 96.70 & 4.93 \\
Grand mean & 98.25 & 3.05 \\
Grand sd & & \\
\hline
\end{tabular}

observed for the number of male florets and total florets, respectively. This only means that the number of florets varies significantly from the mean. An inflorescence may contain as few as 15 florets to as many as 184 florets. Female flowers ranged only from 0-18 and a standard deviation of 2.196. Moreover, male florets were more numerous than female florets with a sequentially variable ratio rather than conservative. There is no definite relation from the number of male florets to the number of female florets. Inflorescences with more male florets did not necessarily have more female florets than inflorescences with lesser male buds.

Pedicels of floret buds were in varied lengths from $1.95 \mathrm{~mm}$ to $7.75 \mathrm{~mm}$ with an average of $4.058 \mathrm{~mm}$ (Figure 2). Generally, female florets had longer pedicels than male florets since after pollination, the female grew larger and heavier which needed a stronger branch to hold on to the plant. Petals of $J$. curcas measured an average of $5.902 \mathrm{~mm}$ while the sepals measured an average of $3.94 \mathrm{~mm}$ (Table 3 ). There were five petals and five sepals in a J. curcas 
Table 3. Mean and standard deviation (sd) of the length of pedicel, petal, and sepal of J. curcas

\begin{tabular}{llllll}
\hline & & \multicolumn{3}{c}{ Blocks } & Grand mean/sd \\
\cline { 3 - 5 } & & I & II & III & \\
\hline \multirow{4}{*}{ Mean } & pedicel & 3.75 & 4.43 & 3.99 & 4.06 \\
& petal & 5.88 & 5.89 & 5.93 & 5.90 \\
& sepal & 4.11 & 3.87 & 3.83 & 3.94 \\
\multirow{4}{*}{ sd } & pedicel & 1.68 & 1.32 & 0.81 & 1.33 \\
& petal & 0.88 & 0.87 & 0.70 & 0.81 \\
& sepal & 0.85 & 0.77 & 0.63 & 0.75 \\
\hline
\end{tabular}

Block 1: 10 plant samples [2 inflorescences per plant (20 inflorescence samples)] Block 2: 10 plant samples [2 inflorescences per plant (20 inflorescence samples)] Block 3: 7 plant samples [2 inflorescences per plant (14 inflorescence samples)]

flower. Pollens of J. curcas were yellow in color with a spheroidal shape. Pollens were of inaperturate, crotonoid type of ornamentation comprising of some raised, often triangular, sexine elements at the outline (Figure 3).

\section{Blooming Habits}

Number of days required for blooming of all florets in an inflorescence and duration of inflorescence opening

Table 4 shows the mean number of days for blooming of all florets in an inflorescence. It was observed that it took an average of 9.56 days for all florets to fully open. All buds, regardless of number, took 5-13 days to bloom, that is, the opening of the first bud and the last bud in an inflorescence. The number of floret buds did not influence the number of days required for blooming of all florets in an inflorescence. An inflorescence with 100 buds may set faster than an inflorescence with 50 buds in an inflorescence.

Time of the day and duration of opening of individual florets

Shown in Table 5 is the time and duration of opening of an individual floret. On ordinary normal days, it was observed that most flowers fully bloomed early morning before sunrise at around 5-6 in the morning. Due to 
Floral biology of Jatropha curcas L.

Table 4. Mean and standard deviation of the number of days required for blooming of all florets of $J$. curcas

\begin{tabular}{lcc}
\hline & $\begin{array}{l}\text { Mean number of days required } \\
\text { for blooming of all florets }\end{array}$ & Standard deviation \\
\hline Block 1 & 9.25 & 1.71 \\
Block 2 & 9.50 & 1.79 \\
Block 3 & 10.07 & 1.77 \\
Grand mean & 9.56 & 1.75 \\
Grand sd & & \\
\hline
\end{tabular}

some limitations, anthesis was not observed during this time. Flower opening greatly depended on the available sunlight. During cloudy days when there is less sunlight, anthesis started late at around 6 AM while some even later at 8 AM with at most 3 hours duration from anthesis to full blooming (Figure 4). Same is true when rain was experienced in the early morning.

At anthesis, an initial opening like a slit was observed. For 3 hours, the slit gradually widened until all the petals folded and exposed the anthers and stigmas thus, making it a fully bloomed floret. Male flowers remained attached to the stem for at least 24 to 72 hours after which they wilt and fall off. On the other hand, female flowers did not fall off and only the petals and sepals withered.

\section{Time and duration of anther dehiscence}

The powdery condition of the anther was used as an index for anther dehiscence. It was observed that anthers started to dehisce pollen at the time of opening of the male flowers. The duration of dehiscence was also affected by the environment. Dehiscing of pollen lasted from 24 to 73 hours (Table 6). When there was rain, pollen grains were easily washed off from the anthers causing a shorter dehiscence period. Another factor that affected the duration of anther dehiscence was the number and frequency of visits of pollinators such as bees, wasps and ants. The more pollinators and the more flowers visited resulted in a shorter time of anther dehiscence.

The anthers from a single clump separated and became horizontally oriented away from each other. In the course of anther dehiscence, the anthers changed color from yellow (color of pollen) to brown (Figure 5). The 

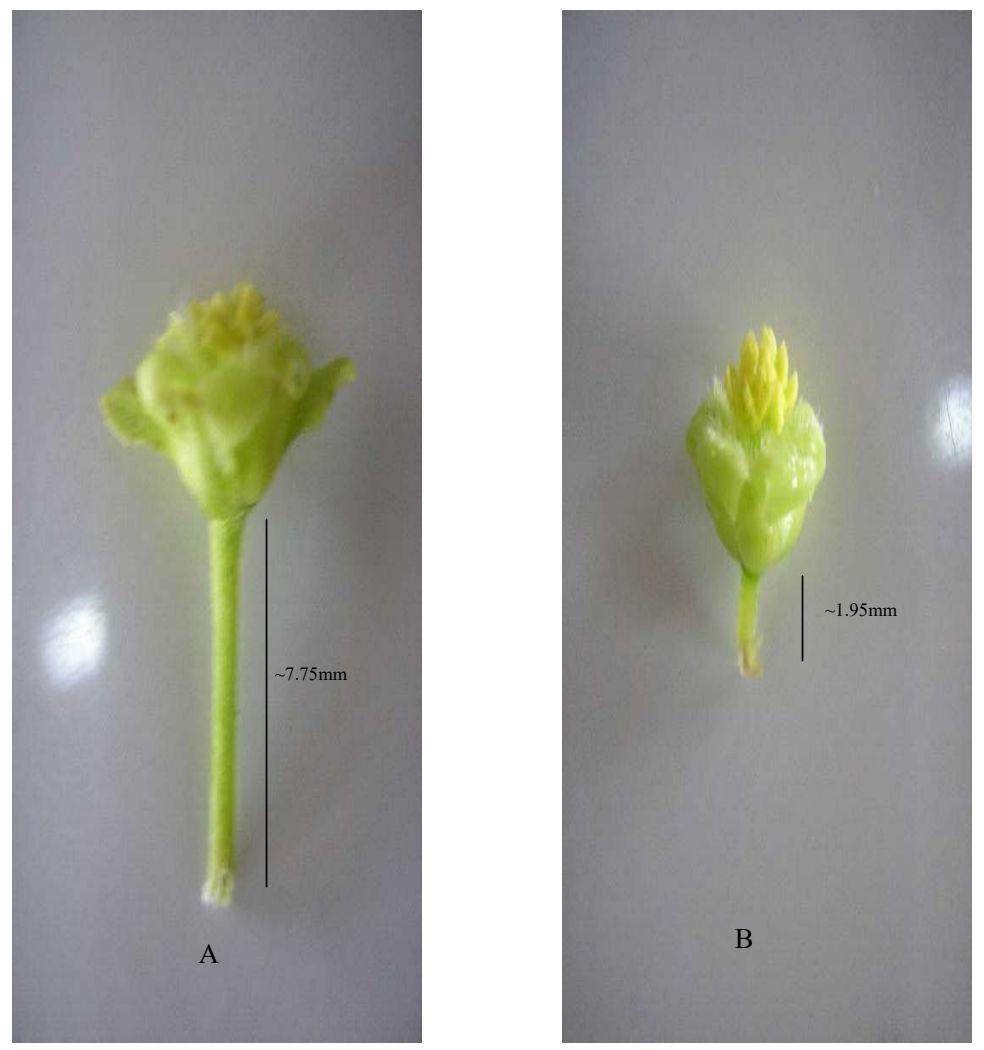

Figure 2. Different lengths of pedicels of J. curcas: A- longer pedicel length of $\sim 7.75 \mathrm{~mm}$ and; B- shorter pedicel length of $\sim 1.95 \mathrm{~mm}$. 


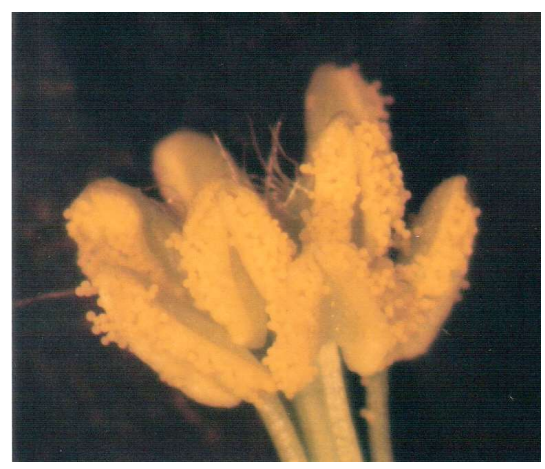

A

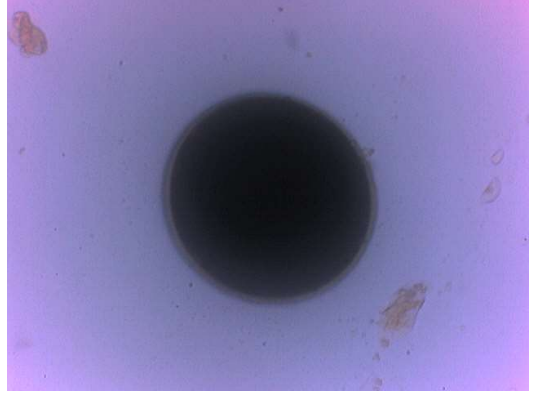

B

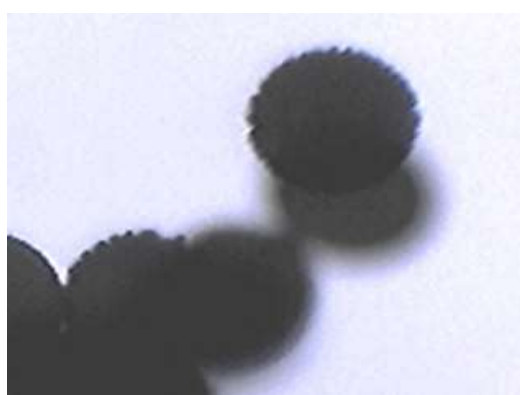

$\mathrm{C}$

Figure 3. Anthers of $J$. curcas exposing yellow and round pollen grains ready to be dehisced (A); pollen showing its ovoid shape; 400x (B) and; pollen of inaperturate, crotonoid type of ornamentation comprising of some raised, often triangular, sexine elements at the outline; 400x (C). 


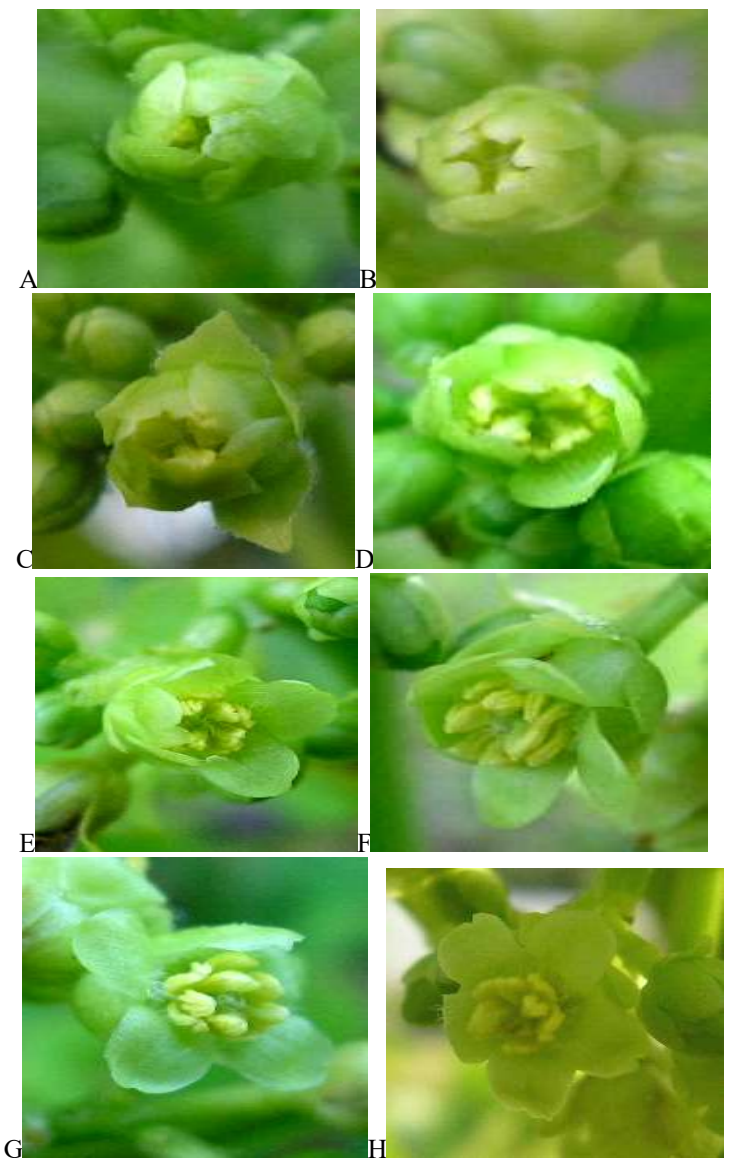

Figure 4. Different stages of flower opening of J. curcas: A. at the start of anthesis; B. about 30 minutes from start of anthesis; $\mathrm{C}$. about 1 hour from start of anthesis; D. about 1 hour and 30 minutes from start of anthesis; E. about 2 hours from start of anthesis; F. about 2 hours and 30 minutes from start of anthesis; G. a few minutes before fully bloomed; $\mathrm{H}$. fully bloomed floret. 
Floral biology of Jatropha curcas L.

Table 5. Mean time of the day and duration of opening of individual florets of J. curcas.

\begin{tabular}{lllc}
\hline & Time of anthesis & $\begin{array}{l}\text { Time of floret } \\
\text { full opening }\end{array}$ & Duration of opening \\
\hline Block 1 & not observed & $5: 35 \mathrm{AM}$ & $\mathrm{NA}^{*}$ \\
Block 2 & $5: 45 \mathrm{AM}$ & $8: 45 \mathrm{AM}$ & 3 hours \\
Block 3 & $6: 05 \mathrm{AM}$ & $9: 00 \mathrm{AM}$ & 2 hours and 55 minutes \\
\hline
\end{tabular}

*NA- not applicable

Block 1: 10 plant samples [2 inflorescences per plant (20 inflorescence samples)] Block 2: 10 plant samples [2 inflorescences per plant (20 inflorescence samples)] Block 3: 7 plant samples [2 inflorescences per plant (14 inflorescence samples)]

change in color indicated the amount of pollen to be dehisced. When the anthers were yellow, there were still much pollen to be dehisced or this indicated that pollen dehiscence has just started. However, when anthers became lighter yellow, much of the pollen had already been released. The outline/edges of the anthers then turned brownish denoting that anther dehiscence had stopped. Afterwards, the yellowish anthers changed color to brown and withered (Figure 6). Soon after, other parts of the flower also withered and fell off.

\section{Time and duration of stigmatic receptivity}

The stigmas of $J$. curcas were dark green in color. Some of the female flowers had their stigmas sticking out of the petal covering before anthesis. By then, the stigmas were not yet receptive. Like the anthers of the male flower, the stigmatic branches were connate or clumped into one but separated upon flower opening as shown in Figure 7. These gave the more exposed bifurcated stigma a higher chance of being pollinated. Stigmatic receptivity started about 1-2 hours after florets had fully bloomed. Although it was quite indistinct in the field, the presence of muscilaginous substance indicated that stigma is already receptive. During receptivity, the stigma has a 'wet look' appearance. Stigmatic receptivity was observed to last for about 24 hours or less (Figure 9). During the first few hours of receptivity, insect pollinators were observed to frequently visit the flower, transferring pollen grains to stigmas. Few specks of pollen 
Table 6. Mean time and duration of anther dehiscence of J. curcas

\begin{tabular}{llll}
\hline & $\begin{array}{l}\text { Mean duration of } \\
\text { anther dehiscence } \\
\text { (hours) }\end{array}$ & $\begin{array}{l}\text { Range } \\
\text { (hours) }\end{array}$ & $\begin{array}{l}\text { Standard } \\
\text { deviation } \\
\text { (sd) }\end{array}$ \\
\hline Block 1 & 49.90 & $25.50-73$ & 14.23 \\
Block 2 & 41.07 & $25-59$ & 13.38 \\
Block 3 & 33.65 & $24-49$ & 9.36 \\
$\begin{array}{l}\text { Grand mean } \\
\text { Grand sd }\end{array}$ & 41.54 & & 13.83 \\
\hline
\end{tabular}

were observed after insect pollinators have gone away. After about 24 hours, stigma color turned from green to black, signifying that the flower had already been pollinated.

It is important to know when is the right time for a successful pollination. As reported by Bhattacharya, et. al. (2005), J. curcas is predominantly cross-pollinated plant and this is clearly shown in many of its reproductive traits such as high abortion rate and apomixes, high attractiveness to pollinators, delayed stigma receptive period, and morphological differentiation of receptive stigma for proper pollen reception.

A trial and error method of six samples of female flowers were hand pollinated at different times at a 30-minute interval (5:30 AM; 6; 6:30 AM; 7 AM; 7:30 AM; 8 AM). As shown in Table 7, the female flowers pollinated at 5:30 in the morning did not develop into a fruit while the rest did. This probably happened because the stigma was not yet receptive that time and was not pollinated again during its receptive period thus, no fertilization took place. As discussed earlier, flowers of J. curcas opened around $5 \mathrm{o}$ ' clock in the morning and female flowers became receptive an hour or two after opening. The rest of the samples were successfully pollinated which indicated that stigmas during those times were already receptive. However, this finding did not conform with the results of a study done by Bhattacharya, et. al. (2005), since their results showed that stigmatic receptivity started about 2 hours from opening of the female flower. The variation in the stigmatic receptivity was perhaps due to differences in environment at different places. 

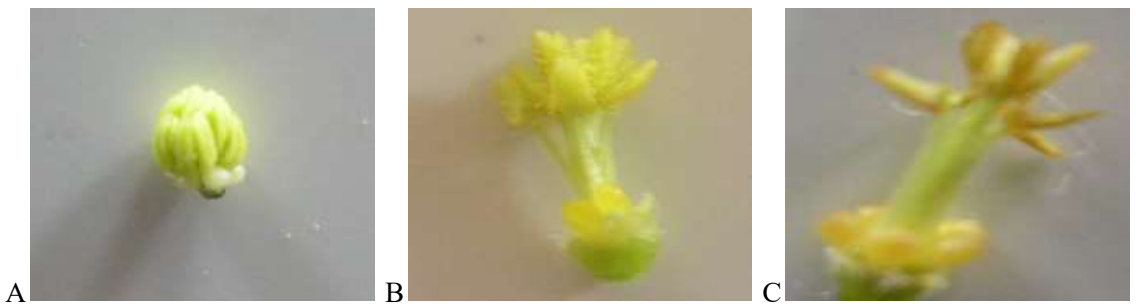

Figure 5. Anthers from being a single clump (A); then opened and separated (B) and changed color from yellow to brown (C).
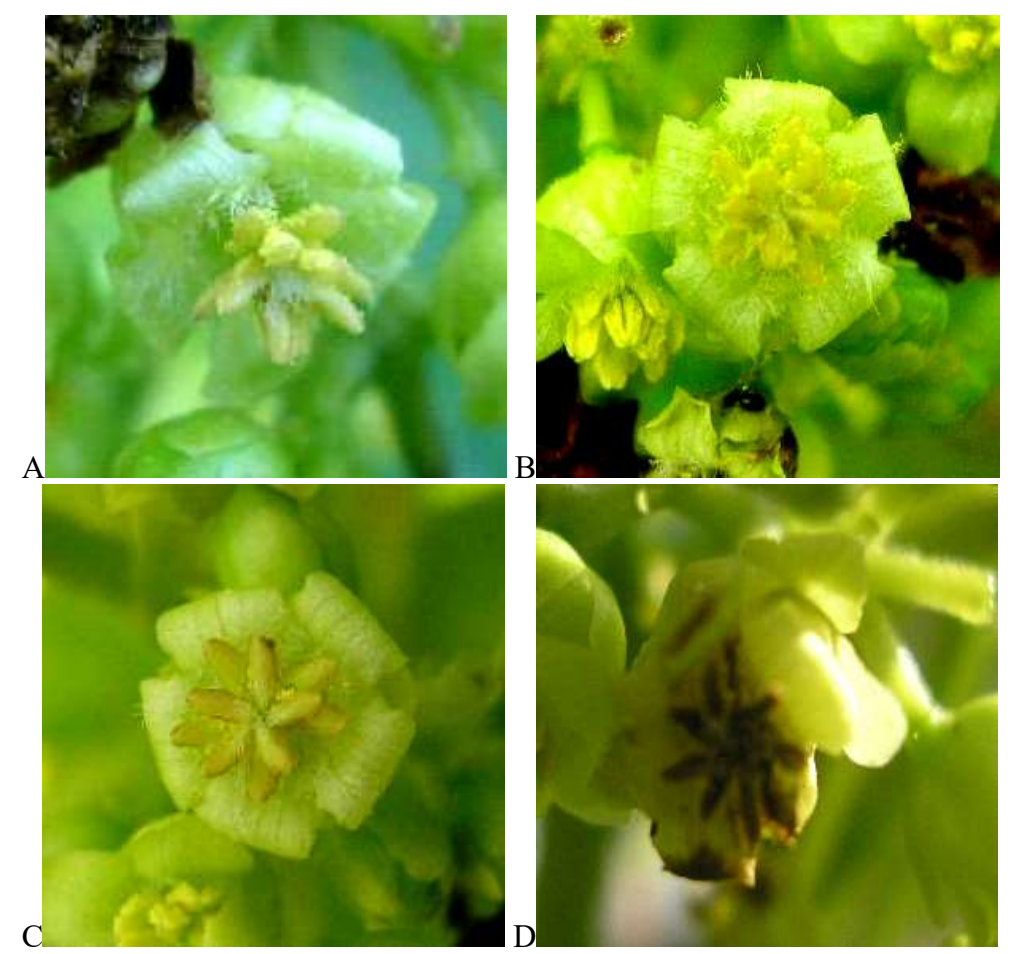

Figure 6. Pollen dehiscence of $J$. curcas: A. flower has just started dehiscing pollen; B. a few hours of pollen dehiscence (still yellow in color); C. after 24-48 hours of pollen dehiscence; D. after 48-72 hours of pollen dehiscence (anthers withered already). 

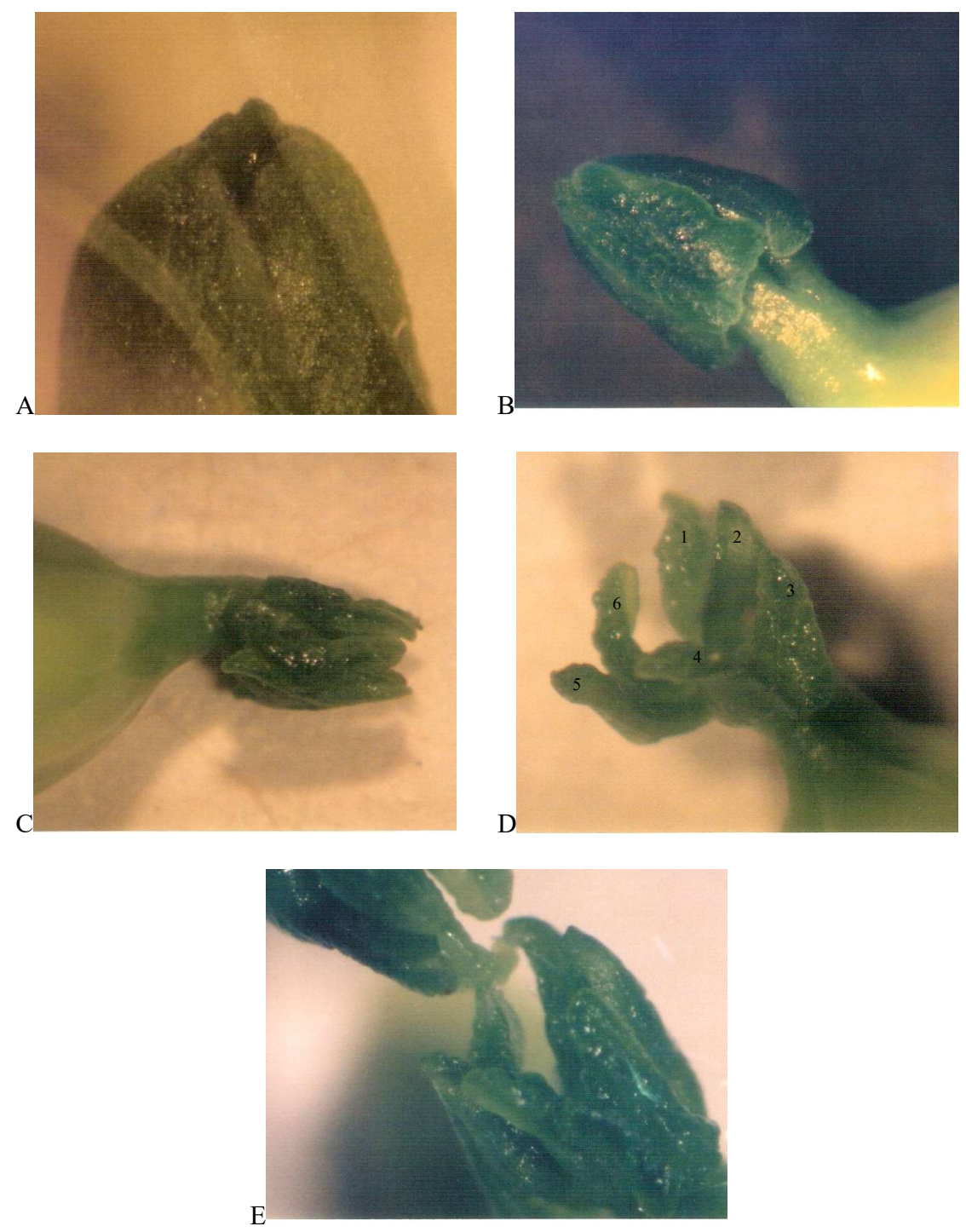

Figure 7. Stigma of J. curcas: A. stigma sticking out of the petal but are not yet receptive; B. a clump of stigma before flower opening; C. stigma starting to separate; D. stigma already separated showing its bifurcated structure (6 end point) and; E. 'wet look' receptive stigma. 

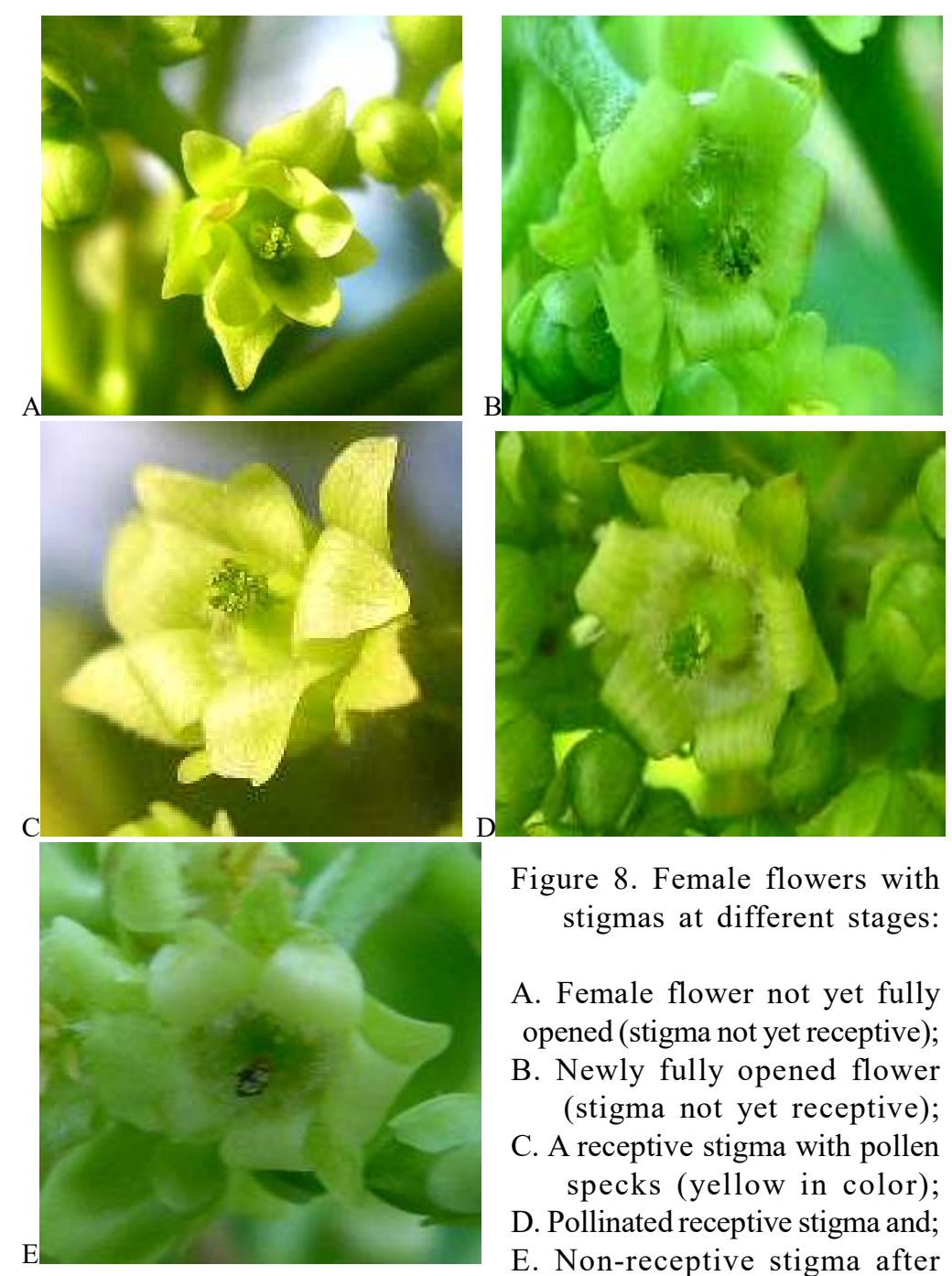

Figure 8. Female flowers with stigmas at different stages:

A. Female flower not yet fully opened (stigma not yet receptive); B. Newly fully opened flower (stigma not yet receptive);

C. A receptive stigma with pollen specks (yellow in color);

D. Pollinated receptive stigma and;

E. Non-receptive stigma after about 24 hours from pollination (note the change in color). 

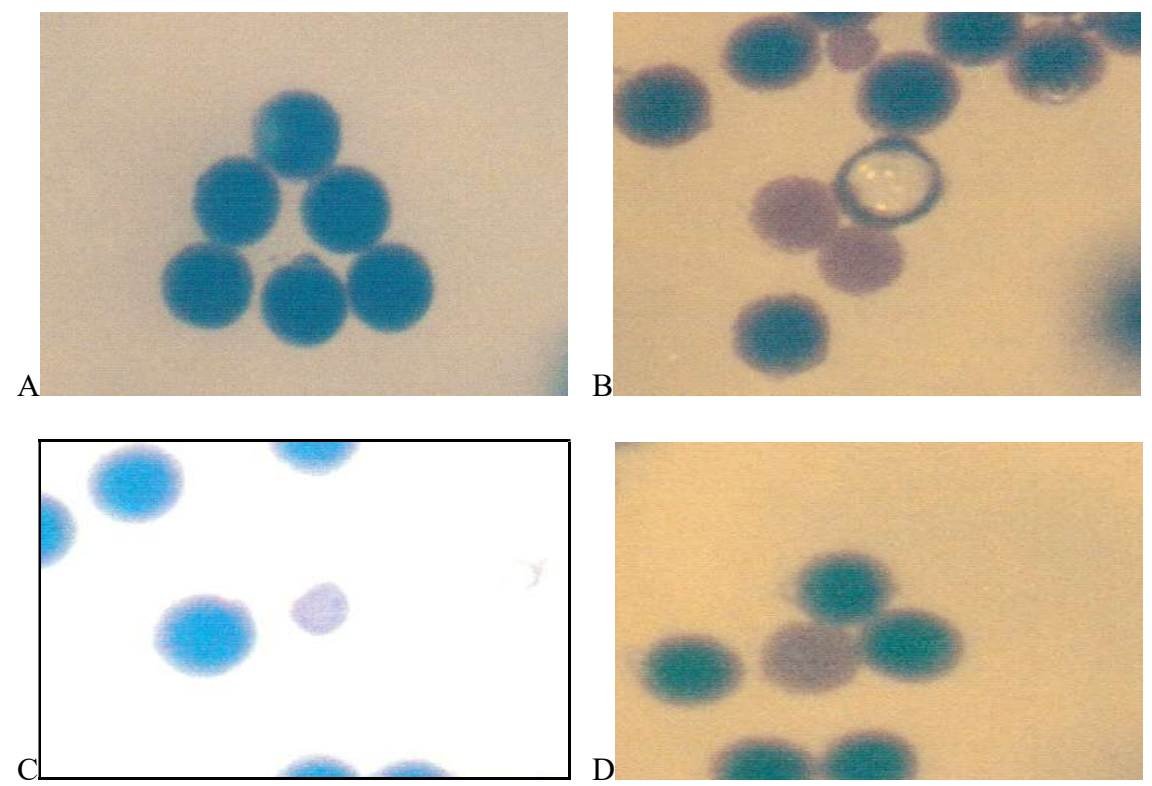

Figure 9. Pollen viability test (100x): A. viable pollen grains, dark blue in color due to presence of starch; B. a couple of non-viable pollen, yellow in color; C. non-viable pollen that is deformed; D. difference in color of viable and nonviable pollen very distinct.
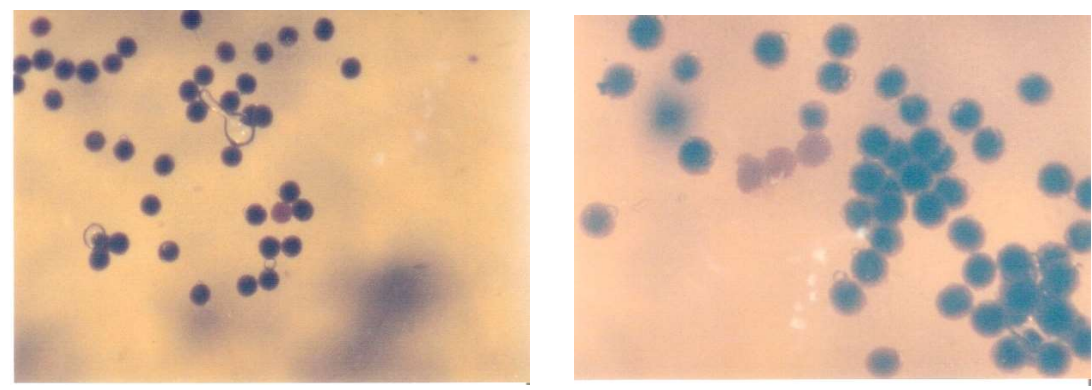

Figure 10. Pollen viability test showing that majority of the pollen grains were viable (dark colored) giving a mean of $93.92 \%$ viability. Magnification: $40 \mathrm{x}$ 
Table 7. Hand pollination of $J$. curcas at different times at a 30-minute interval

\begin{tabular}{lll}
\hline Time & Trial 1 & Trial 2 \\
\hline 5:30 AM & Unsuccessful & Unsuccessful \\
6:00 AM & Developed into a fruit & Unsuccessful \\
6:30 AM & Developed into a fruit & Developed into a fruit \\
7:00 AM & Developed into a fruit & Developed into a fruit \\
7:30 AM & Developed into a fruit & Developed into a fruit \\
8:00 AM & Unsuccessful & Developed into a fruit \\
\hline
\end{tabular}

\section{Pollen viability}

Viable pollens turned dark blue/violet while non-viable pollens remained yellow and some were deformed. Viable pollens turned blue due to the presence of starch/carbohydrate which indicated that they are still capable of germination. As shown in Figure 10, the color difference of viable and nonviable pollen was very distinct. Table 8 reflects the mean pollen viability of $J$. curcas collected at anthesis. High percent pollen viability was observed with a mean of $93.916 \%$. Also shown in Figure 11, majority of the collected pollens were viable. Most were stained dark blue and only a few remained yellow. This means that there was higher percentage of viable pollens transferred to the female flower for a successful pollination.

\section{Meteorological data in relation to the flowering of Jatropha curcas $L$.}

During the conduct of the study, the climate at LSU was favorable for the flowering of Jatropha curcas. Generally, the climate was dry with only a little rain except on the 5th week (May 7-13) when there was typhoon, pouring a total of $462.4 \mathrm{~mm}(66 \mathrm{~mm} /$ day $)$ of rainfall. This condition resulted in the decreased percent floret set since floret buds fell off due to heavy rain. That week also had less sunshine compared to other weeks and there was no sunshine observed for 2 days (May 11 and 12). During these periods, fewer flowers opened since blooming of $J$. curcas was greatly influenced by sunlight among others.

The average minimum and maximum air temperatures were recorded to be $25^{\circ} \mathrm{C}$ and $32.79^{\circ} \mathrm{C}$, respectively, with an average relative humidity of $77.7 \%$ 
Table 8. Mean percent pollen viability of $J$. curcas

\begin{tabular}{lcc}
\hline & Mean percent viability & Standard deviation (sd) \\
\hline Block 1 & 95.77 & 2.43 \\
Block 2 & 92.96 & 2.68 \\
Block 3 & 93.01 & 3.04 \\
Grand mean & 93.92 & 2.87 \\
Grand sd & & \\
\hline
\end{tabular}

Block 1: 10 plant samples [2 inflorescences per plant (20 inflorescence samples)] Block 2: 10 plant samples [2 inflorescences per plant (20 inflorescence samples)] Block 3: 7 plant samples [2 inflorescences per plant (14 inflorescence samples)]

during the conduct of the study. Sunshine plays a vital role in the blooming habits of J. curcas. Based on the meteorological data gathered, there was a total of 23,604 minutes (393.4 hours) of sunshine during the conduct of the study (April 9- June 10) with an average of 377.507 minutes ( 6.29 hours) per day. These conditions were observed to be conducive to floral blooming of $J$. curcas.

\section{CONCLUSION}

$J$. curcas flowers are light greenish white in color with the male and female flowers borne on the same plant. Male flowers have 10 anthers arranged in two whorls of five each while female flowers have green bifurcated stigmas. The time and duration of flower opening, anther dehiscence, and stigmatic receptivity were affected by the environment. Opening of flowers takes place in the early morning while anther dehiscence continues for 24-72 hours and stigmatic receptivity, lasting for 24 hours. Pollen viability is considerably high ranging from $88.12-98.55 \%$.

\section{ACKNOWLEDGMENT}

This paper was funded by the "Jatropha Project" through Dr. Roberto Guarte. The authors would like to thank Dr Rodrigo F. Sebidos, Dr. Rodolfo G. Escalada and Prof. Algerico M. Mariscal. The author is likewise thankful to Ms. Flora Mia Y. Duatin and Ms. Carmille Joanna C. Bales for the lay-outing 
and editing of the pictures. Dr. Beatriz Belonias, Dr. Marilyn Belarmino, Mr. Bebot Braga and Prof. Elvira Oclarit for the assistance in the laboratory and to Mr. Felixberto Malasaga, for the assistance in the field.

\section{REFERENCES}

BHATTACHARYA, A., K. DATTA and S. K. DATTA. 2005. Floral Biology, Floral Resource Constraints and Pollination Limitation in Jatropha curcas L. Pakistan Jour. of Biol. Sci., 8 (3): 456-460.

DEHGAN, B. and G. L. WEBSTER. 1979. Morphology and infragenic relationships of the genus Jatropha (Euphorbiaceae). Univ. of Calif. Publ. in Botany Vol. 74.

DUKE, J. A. and K. K. WAIN. 1981. Medicinal plants of the world. Computer index with more than 85,000 entries. 3 vol. www.hort.purdue.edu, accessed: January, 2007

ECOPORT.ORG. accessed: January, 2007

GRIMM, C., 1999. Evaluation of damage to physic nut (Jatropha curcas) by tree bugs. Entomologia Experimentalis et Applicata 92:127-136.

HELlER, J. 1996. Physic nut. Jatropha curcas L. Promoting the conservation and use of underutilized and neglected crops. Institute of Plant Genetics and Crop Plant Research, Gatersleben, International Plant Genetic Resources Institute, Rome.

JEPSEN, J. K., R. K. HENNING and B. NYATHI. 2003. Generative propagation of Jatropha curcas L. on Kalahari Sand. www.jatropha.com, accessed: January, 2007.

JOKER, D. and J. JEPSEN. 2003. Jatropha curcas L. Seed Leaflet No. 83 August 2003. Danida Forest Seed Centre. Denmark.

MAKKAR, H. P. S., K. BECKER and B. SCHMOOK. 2001. Edible provenances of Jatropha curcas from Quintna Roo State of Mexico and effect of roasting on antinutrient and toxic factors in seeds. Institute for Animal Production in the Tropics and Subtropics (480), University of Hohenheim, D-70593 Stuttgart, Germany.

NATIONAL SCIENCE AND TECHNOLOGY AUTHORITY. 1982 Guidebook on the Proper Use of Medicinal Plants. NSTA. Bicutan, Taguig, Metro Manila. 142pp.

netfiles.uiuc.edu, accessed: January, 2007.

NORIEL, L. M., E.A. VASQUEZ, F. M. Y. DUATIN and G. O. SOPSOP. 1998. Ethnobotanical knowledge of farmers in Baybay, Leyte. In: Proceedings of the International Conference of Applied Tropoical Ecology. Sept. 8-10,1998, Visca, Baybay, Leyte. 268-277. 
ROCKEFELLER FOUNDATION. 1998. The potential of Jatropha curcas in rural development and environment protection- An Exploration. Concept paper. Rockefeller Foundation and Scientific and Industrial Research and Development Centre, Harare, Zimbabwe 1998.

WATT, J. M. AND M. G. BREYER-BRANDWIJK. 1962. The Medicinal and Poisonous Plants of Southern and Eastern Africa. (2nd ed). E\&S. Livingstone, Ltd, Edinburgh and London. www.hort.purdue.edu, accessed: January, 2007. 